\title{
Mortality rate trends in patients diagnosed with schizophrenia or bipolar disorder: a nationwide study with 20 years of follow-up
}

Line Hosbond Lomholt ${ }^{1}$, Diana Vincens Andersen ${ }^{1}$, Christina Sejrsgaard-Jacobsen ${ }^{1}$, Cagla Margit Øzdemir ${ }^{1}$, Claus Graff ${ }^{2}$, Ole Schjerning ${ }^{3}$, Svend Eggert Jensen 1,3, Sune Puggard Vogt Straszek ${ }^{1,3}$, Rasmus W. Licht ${ }^{1,3}$, Simon Grøntved ${ }^{3}$ and René Ernst Nielsen ${ }^{1,3^{*}}$ (D)

\begin{abstract}
Background: Patients with severe mental illness (SMI) have a reduced life expectancy of one to two decades as compared to the general population, with most years of life lost due to somatic diseases. Most previous studies on disorders constituting SMI, e.g. schizophrenia and bipolar disorder, have investigated the disorders separately and hence not compared the disorders in terms of mortality rates relative to the background population.

Methods: A register-based cohort study including the entire Danish population comparing mortality rates relative to the background population, controlling for age and sex, i.e. standardized mortality ratios (SMRs) in patients diagnosed with schizophrenia with those in patients diagnosed with bipolar disorder, during the study period from 1995 to 2014.

Results: The SMR of patients with SMI was significantly higher than one for each calendar year in the study period with an overall SMR of $4.58,95 \% \mathrm{Cl}(4.48-4.69)$ in patients diagnosed with schizophrenia $(n=38,500)$ and of 2.57 $(95 \% \mathrm{Cl} 2.49-2.65)$ in patients diagnosed with bipolar disorder $(n=23,092)$. When investigating time trends in SMR for schizophrenia and for bipolar disorder, respectively, an increase in SMR over time was shown with a mean increase of 0.03 per year for schizophrenia and 0.02 for bipolar disorder ( $p<0.01$ for both disorders). The ratio between SMR for schizophrenia and SMR for bipolar disorder for each calendar year over the study period was constant $(p=0.756)$.
\end{abstract}

Conclusions: Increasing SMRs over the last 20 years were found for both patients diagnosed with bipolar disorder and patients diagnosed with schizophrenia. Despite clear differences between the two disorders regarding SMRs, the increases in SMR over time were similar, which could suggest similar underlying factors influencing mortality rates in both disorders.

Keywords: Bipolar disorder, Schizophrenia, Epidemiology, Mortality

\footnotetext{
*Correspondence: ren@rn.dk

${ }^{3}$ Department of Psychiatry, Aalborg University Hospital, Mølleparkvej 10,

9000 Aalborg, Denmark

Full list of author information is available at the end of the article
} 


\section{Background}

Patients diagnosed with bipolar disorder and patients diagnosed with schizophrenia, constituting a group of patients with severe mental illness (SMI), have a reduced life expectancy of one to two decades as compared to the background population (Nordentoft et al. 2013). There is a large increased relative risk of suicide or accidents as the cause of death, but most years of life lost are attributable to somatic disorders, similar to the findings in the general population (Nordentoft et al. 2013). Specialized treatment interventions have been shown to be effective in reducing the psychiatric outcomes as relapse and hospitalization (Kessing et al. 2013; Correll et al. 2018), but so far outcome data on mortality and somatic morbidity have not been reported. Patients with severe mental illness have an increased rate of poor life style such as lack of exercise, poor diet, increased occurrence of smoking and obesity, resulting in increased rates of chronic somatic diseases leading to excess mortality rates (Mitchell et al. 2015; Vancampfort et al. 2015, 2016, 2017). In a recent study by Speyer et al. no effect of care coordination and lifestyle coaching was seen on the primary outcome of 10-year risk of cardiovascular disease when compared to treatment as usual (Speyer et al. 2016). In the study by Kugathasan et al. investigating long-term outcome after myocardial infarction in patients with schizophrenia, no difference in short-term outcome compared to patients experiencing myocardial infarction but not diagnosed with schizophrenia was shown, whereas an increased long term mortality was reported (Kugathasan et al. 2018). The study by Jakobsen et al. showed similar results and showed furthermore no difference in the in-hospital treatment between patients with SMI and the background population, whereas a lower percentage of patients with SMI received the recommended medical treatment during follow-up resulting in an increased risk of new adverse cardiac events (Jakobsen et al. 2017).

Most studies have reported life expectancy or mortality rates for psychiatric disorders separately and not investigated the mortality for several disorders to compare the disorders with each other. Several studies have shown an increasing mortality gap between patients diagnosed with schizophrenia, patients diagnosed with bipolar disorders and comparative non-psychiatric populations (Nielsen et al. 2013; Hayes et al. 2017). We have previously studied the time trends of standardized mortality ratios (SMRs), i.e. mortality relative to the background population controlling for age and gender, in patients diagnosed with bipolar disorder over the last 20 years (Staudt Hansen et al. 2018). In the current study, we aimed at investigating SMRs for each single year from 1995 to and including
2014 for both schizophrenia and bipolar disorder. Furthermore, we aimed at comparing the two disorders regarding time trends in the SMRs over the study period.

\section{Methods \\ Design}

A register-based cohort study including the entire Danish population.

\section{Study population}

All patients registered with a schizophrenia or bipolar disorder diagnosis in the Danish Psychiatric Central Research Registry (DPCRR) from 1965 until the end of 2014, living in Denmark, alive and below the age of 65 years in the study period from 1995 to 2014 were defined as the severe mental illness population and included in the current study.

Included patients reaching the age of 65 years during the study period were censored at that time point. Schizophrenia was defined as an ICD-8 300.x diagnosis in the period 1965 to end of 1994 or and ICD-10 F20.x diagnosis in the period 1995 to end of 2014. Bipolar disorder was defined as an ICD-8 296.x diagnosis in the DPCRR in the period 1965 to the end of 1994 or an ICD-10 F30.x or F31.x diagnosis in the period 1995 to the end of 2014, resulting in the inclusion of both incident and prevalent cases in contact with hospital-based in- or out-patient treatment facilities. If patients were diagnosed with both bipolar disorder and schizophrenia, patients were analyzed according to the schizophrenia diagnosis.

\section{Registers utilized}

Data on psychiatric contacts were retrieved from the DPCRR (Mors et al. 2011) and the Danish National Patient Register (Lynge et al. 2011).

Data on date of deaths of patients and background population were retrieved from the Danish Civil Registration System (Pedersen 2011).

All inhabitants of Denmark have a unique person identification number-civil person registration number (CPR) - that enables linkage between registers.

\section{Statistical analyses}

The standardized mortality ratio (SMR) for the whole study period was calculated separately for patients diagnosed with schizophrenia and for patients diagnosed with bipolar disorder as the observed number of deaths among patients with either schizophrenia or bipolar disorder divided by the expected number of deaths based on the age and gender specific mortality rates of the general population (Naing 2000). Secondly, time trends of SMR during the 20-year follow-up period were assessed using random effects linear regression, with SE as random 
effect (Juliouset al. 2001), setting the significance level of the $p$ value of the slope $<0.05$, for each of the two diagnostic groups. Lastly, time trends of ratios of annual SMR for schizophrenia to annual SMR for bipolar disorder during the 20-year follow-up period were assessed using random effects linear regression, with $\mathrm{SE}$ as random effect (Julious et al. 2001), setting the significance level of the p-value of the slope $<0.05$.

Data management and statistical analyses were performed in Stata 15 (StataCorp, College Station, TX, USA).

\section{Results}

The total population consisted of 6,176,414 persons with 38,500 patients $(23,625$ male and 14,875 female) with a schizophrenia diagnosis and 23,092 (9510 male and 13,582 female) patients with a bipolar disorder diagnosis alive in the period 1995 to 2014.

The SMR of patients with SMI was significantly higher than one for each calendar year in the study period (Table 1), with an overall SMR of 4.58, 95\% CI (4.48-4.69) in patients diagnosed with schizophrenia and 2.57 (95\% CI 2.49-2.65) in patients diagnosed with bipolar disorder for the whole study period.
When investigating time trends in SMRs for schizophrenia and bipolar disorder respectively an increase in SMR over time was shown with a mean increase of $0.03, \mathrm{p}<0.01$, in SMR per year in patients diagnosed with schizophrenia and $0.02, \mathrm{p}<0.01$, in SMR per year in patients diagnosed with bipolar disorder, as shown in Fig. 1.

The ratio between annual SMRs for schizophrenia over the study period and annual SMRs for bipolar disorder over the study period was unchanged over the study period $(\mathrm{p}=0.7560)$, as shown in Fig. 2.

\section{Discussion}

In this nationwide study including more than 65,000 patients diagnosed with SMI below the age of 65, the overall mortality rate was more than four times higher for patients diagnosed with schizophrenia and more than two-and-a-half times higher for patients diagnosed with bipolar disorder than that of the general population, standardized for age and gender. Furthermore, the increase in annual SMRs over the study period was similar in the two groups diagnosed with SMI. Accordingly, the ratio between the annual SMRs for the two psychiatric populations was unchanged over time.

Table 1 Standardized mortality ratios in the study period for patients diagnosed with schizophrenia and patients diagnosed bipolar disorder, respectively

\begin{tabular}{|c|c|c|c|c|c|c|c|c|c|c|}
\hline \multirow[t]{2}{*}{ Year } & \multicolumn{5}{|c|}{ Schizophrenia } & \multicolumn{5}{|c|}{ Bipolar disorder } \\
\hline & Obs deaths & Exp deaths & SMR & $95 \%$ & & Obs deaths & Exp deaths & SMR & $95 \%$ & \\
\hline 1995 & 278 & 67.25 & 4.13 & 3.68 & 4.65 & 279 & 121.60 & 2.29 & 2.04 & 2.58 \\
\hline 1996 & 265 & 68.95 & 3.84 & 3.41 & 4.34 & 299 & 115.51 & 2.59 & 2.31 & 2.90 \\
\hline 1997 & 303 & 70.52 & 4.30 & 3.84 & 4.81 & 253 & 108.64 & 2.33 & 2.06 & 2.63 \\
\hline 1998 & 309 & 71.51 & 4.32 & 3.86 & 4.83 & 243 & 104.42 & 2.33 & 2.05 & 2.64 \\
\hline 1999 & 348 & 74.31 & 4.68 & 4.22 & 5.20 & 250 & 102.31 & 2.44 & 2.16 & 2.77 \\
\hline 2000 & 316 & 75.20 & 4.20 & 3.76 & 4.69 & 212 & 97.53 & 2.17 & 1.90 & 2.49 \\
\hline 2001 & 357 & 78.25 & 4.56 & 4.11 & 5.06 & 238 & 94.60 & 2.52 & 2.22 & 2.86 \\
\hline 2002 & 370 & 81.58 & 4.54 & 4.10 & 5.02 & 252 & 91.85 & 2.74 & 2.42 & 3.10 \\
\hline 2003 & 400 & 84.71 & 4.72 & 4.28 & 5.21 & 248 & 89.62 & 2.77 & 2.44 & 3.13 \\
\hline 2004 & 409 & 86.25 & 4.74 & 4.30 & 5.22 & 241 & 87.22 & 2.76 & 2.44 & 3.14 \\
\hline 2005 & 433 & 84.30 & 5.14 & 4.67 & 5.64 & 201 & 82.94 & 2.42 & 2.11 & 2.78 \\
\hline 2006 & 428 & 89.40 & 4.79 & 4.35 & 5.26 & 236 & 84.30 & 2.80 & 2.46 & 3.18 \\
\hline 2007 & 447 & 93.32 & 4.79 & 4.37 & 5.26 & 222 & 84.95 & 2.61 & 2.29 & 2.98 \\
\hline 2008 & 408 & 90.16 & 4.53 & 4.11 & 4.99 & 245 & 79.95 & 3.06 & 2.70 & 3.47 \\
\hline 2009 & 417 & 92.10 & 4.53 & 4.11 & 4.98 & 196 & 78.44 & 2.50 & 2.17 & 2.87 \\
\hline 2010 & 419 & 92.46 & 4.53 & 4.12 & 4.99 & 195 & 75.31 & 2.59 & 2.25 & 2.98 \\
\hline 2011 & 412 & 88.06 & 4.68 & 4.25 & 5.15 & 195 & 69.74 & 2.80 & 2.43 & 3.22 \\
\hline 2012 & 410 & 86.48 & 4.74 & 4.30 & 5.22 & 176 & 66.87 & 2.63 & 2.27 & 3.05 \\
\hline 2013 & 397 & 85.74 & 4.63 & 4.20 & 5.11 & 174 & 64.81 & 2.68 & 2.31 & 3.11 \\
\hline 2014 & 419 & 85.37 & 4.91 & 4.46 & 5.40 & 180 & 64.07 & 2.81 & 2.43 & 3.25 \\
\hline
\end{tabular}

Obs deaths observed number of deaths, Exp deaths expected number of deaths, SMR standardized mortality ratio, $\mathrm{Cl}$ confidence interval 
6

4

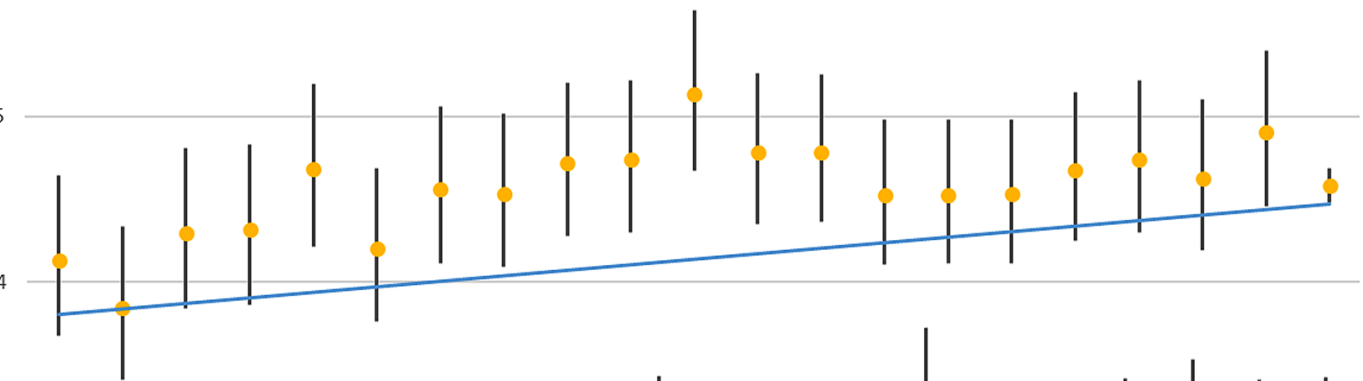

3

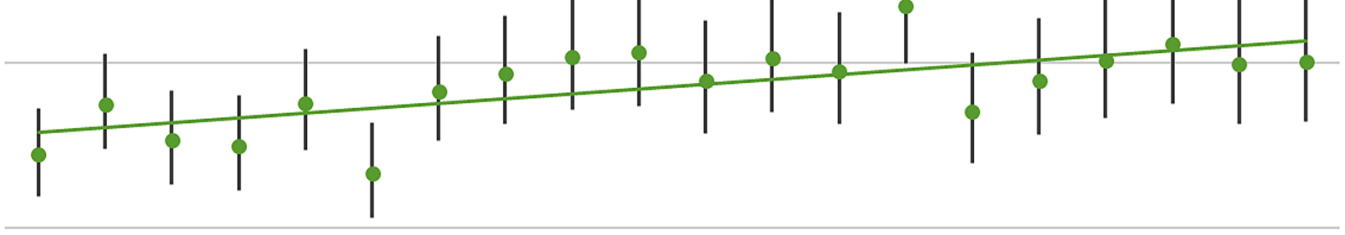

1

$\begin{array}{llllllllllllllllllll}1995 & 1996 & 1997 & 1998 & 1999 & 2000 & 2001 & 2002 & 2003 & 2004 & 2005 & 2006 & 2007 & 2008 & 2009 & 2010 & 2011 & 2012 & 2013 & 2014\end{array}$

Fig. 1 Standardized mortality ratios including 95\% confidence intervals for patients diagnosed with schizophrenia (yellow points) and bipolar disorder (green points) compared to the general Danish population from 1995 to 2014. The dotted lines are fitted utilizing linear regression

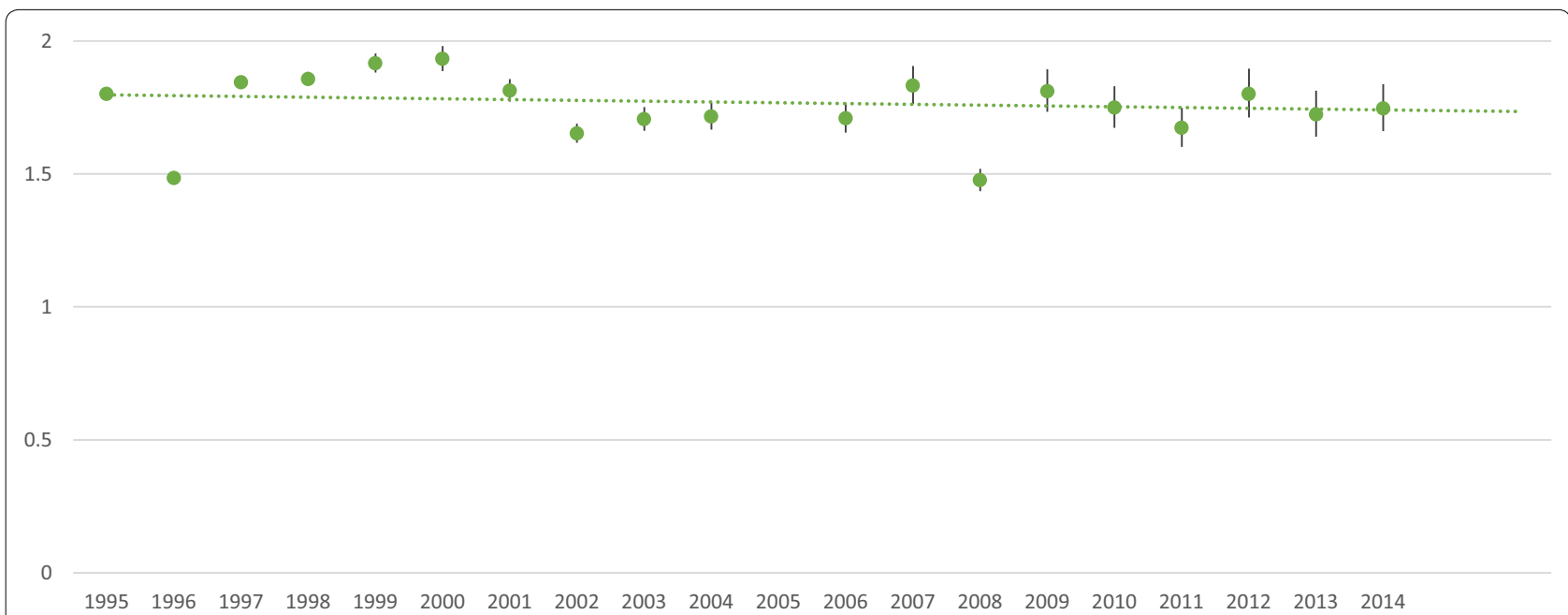

Fig. 2 Ratio of standardized mortality ratio for schizophrenia divided by standardized mortality ratio for bipolar disorder. The dotted line is fitted utilizing linear regression 
Similar to our findings, previous studies have shown increases in the relative mortality gap over time between the patients diagnosed with schizophrenia and bipolar disorder respectively and background populations (Hayes et al. 2015; Lee et al. 2018). Hayes et al. (2017) showed an increased mortality rate in both patients diagnosed with schizophrenia as well as in patients diagnosed with bipolar disorder, but did not find a two-fold difference in relative mortality rates as compared to the background population. Contrary to the currents study, Hayes et al. (2017) utilized several regression models to investigate time trends in mortality rates as well as to adjust to explanatory variables. Lastly, the study by Hayes et al. (2017) supported a general decrease in absolute mortality rates for all investigated, but a larger reduction in absolute mortality rates for the background population, resulting in an increasing mortality gap between patients diagnosed with bipolar disorder or schizophrenia as compared to the background population. Studies have also shown a general lowered life expectancy in patients diagnosed with SMI (Nordentoft et al. 2013), which might have been caused by poorer treatment of physical diseases (Laursen and Nordentoft 2011; Laursen et al. 2013; Kugathasan et al. 2018) and by higher prevalence of physical co-morbidities and more unhealthy lifestyle in patients with SMI as compared to the background population (Mitchell et al. 2015; Vancampfort et al. 2015, 2016, 2017). Poor lifestyle choices like low physical activity (Vancampfort et al. 2017), poor diet (Teasdale et al. 2017), and lack of smoking cessation (Mitchell et al. 2015) are still more prevalent in patients with SMI as compared to the general population. Also, cardiovascular risk factors, diabetes, dyslipidemia and obesity are more prevalent in patients with psychiatric disorders than in the background population, and the associations of these risk factors to psychiatric disorders are not significantly changed by treatment with antidepressants or antipsychotics, and these treatments themselves are associated to risk factors as well (Pérez-Piñar et al. 2016). Studies investigating the effects of life style interventions have been conducted, but have mainly shown disappointing results with lack of changes in risk profiles (Speyer et al. 2016; Ashdown-Franks et al. 2018).

Studies have raised concern regarding disparity in treatment of physical disease for patients with SMI, with a relatively low quality of care for patients with psychiatric diagnoses in general (Mitchell et al. 2014). In patients with SMI and also diagnosed with AIDS, a lowered compliance to medication was observed (Moore et al. 2012), and in patients with non-affective psychotic disorders a lowered prevalence of prescribed somatic medication and fewer consultations with a general practitioner has been observed (Swildens et al. 2016), in patients with SMI disparities in screening for cancer were observed as well as a higher rate of case-fatality, which was not reduced by adjusting for cancer stage and comorbidity (Howard et al. 2010; Manderbacka et al. 2017). In patients with SMI, a lowered rate of invasive cardiac procedures was observed as compared to the background population despite patients being admitted to hospital (Laursen et al. 2009). After treatment of somatic disorders an increased risk of early rehospitalization in patients with SMI was observed for cardiovascular, pulmonary, endocrinological and infectious diseases (Davydow et al. 2016), suggesting an unmet need for treatment or a poorer treatment response as compared to the background population. Patients with SMIs have a well-documented increased rate of mortality mainly as a consequence of somatic illnesses, even when adjusting for stage of illness (Laursen 2011; Wahlbeck et al. 2011). In accordance with these findings, a decreased proportion of patients with severe mental disorders were screened for breast cancer, cervical cancer or general somatic illness as compared to the background population (James et al. 2017; Thomas et al. 2018).

Data support a lack of knowledge of mental disorders as well as a more negative attitude towards patients with mental disorders in nursing staff in somatic care, as compared to nursing staff in mental health (Björkman et al. 2008). These negative attitudes, as well as the lack of integration between somatic and psychiatric treatment centers might result in the disparity in treatment of somatic disorders in patients with SMI, partially influencing mortality, and resulting in patients with SMI not gaining the same effects of reduced mortality as a result of improved treatment for somatic disease as the background population (Fleischhacker et al. 2008).

Our findings suggest that for schizophrenia and bipolar disorder there is a similar increase in mortality gap between the two disorders respectively and the background population. However, by utilizing SMRs as an outcome measure, which reports the relative mortality rates between a specified population and the background population, we were unable to confer if the increasing mortality ratio is a result of patients with SMI having an increased mortality rate absolutely over time or merely a less lowered mortality rate as compared to the background population. The similar time trends in SMR for patients diagnosed with schizophrenia and bipolar disorder could suggest similar underlying factors influencing mortality, although the design and model of analysis do not allow conclusions regarding causality.

\section{Strengths and limitations}

In the current study, inclusion of both incident and prevalent cases was chosen to increase clinical relevance and generalizability of the results. Nationwide 
population-based register studies in Denmark benefit from several factors. First, reporting data to the Danish health care registers is mandatory for all in- or outpatients treated in a hospital-based service treatment. As a result, almost no patients are lost to follow-up. Secondly, in Denmark health care is without any direct cost for the individual, as healthcare is provided and paid as part of the Danish tax system. Consequently, results from Danish studies are not confined to patients with a certain socioeconomic status or patients from specific geographical regions of a larger country as some health insurance database studies might be. The schizophrenia diagnosis has been validated in the Danish healthcare registers (Uggerby et al. 2013), and generally the validity of psychiatric diagnoses is believed to be high (Mors et al. 2011), although no specific validation of the bipolar disorder diagnosis has been conducted. Due to the very long inclusion period, patients were included based on the ICD-8 (first part of the period) and on the ICD-10 (last part of the period). However, those patients diagnosed utilizing ICD-8 criteria might not have constituted the exact same patient group as those being diagnosed according to ICD- 10 .

The primary outcome of SMR carries some limitations. SMR is only adjusted for age and sex, resulting in lack of adjustment for other possible confounders. Utilizing other models would have allowed adjustment for more variables, which though could have obscured the overall effect of, e.g. life style and socio-economic status, which is systematically different in patients with SMI as compared to the background population. With the current model used, the true excess mortality of this disadvantaged patient group is reported. The current findings could be biased by including only patients assigned a register diagnosis. Thus, persons fulfilling criteria for schizophrenia or bipolar disorder, but not diagnosed in a psychiatric setting before death, could have biased the results conservatively.

\section{Conclusion}

Increasing SMRs over the last 20 years were found for both patients diagnosed with bipolar disorder and patients diagnosed with schizophrenia. Despite clear differences between the two disorders regarding SMRs, the increases in SMR over time were similar, which could suggest similar underlying factors influencing mortality rates in both disorders.

\section{Authors' contributions}

All authors contributed to the initial conception and design of the study. REN acquired the data and LHL, DVA, CSJ, CM $\varnothing, C G$ and SG did the initial data analysis. REN completed the first draft of the manuscript and tables. All authors contributed to the editing of the final draft. All authors read and approved the final manuscript.

\begin{abstract}
Author details
${ }^{1}$ Department of Clinical Medicine, Aalborg University, Aalborg, Denmark.

${ }^{2}$ Department of Health Science and Technology, Aalborg University,

Aalborg, Denmark. ${ }^{3}$ Department of Psychiatry, Aalborg University Hospital, Mølleparkvej 10, 9000 Aalborg, Denmark.
\end{abstract}

\section{Acknowledgements \\ None.}

\section{Competing interests}

RW Licht has received research grant from Glaxo Smith Kline, honoraria for lecturing from Pfizer, Glaxo Smith Kline, Eli Lilly, Astra-Zeneca, Bristol-Myers Squibb, Janssen Cilag, Lundbeck, Otsuka, Servier and honoraria from advisory board activity from Glaxo Smith Kline, Eli Lilly, Astra-Zeneca, Bristol-Myers Squibb, Janssen Cilag, and Sunovion. RE Nielsen has received research grants from $\mathrm{H}$. Lundbeck and Otsuka Pharmaceuticals for clinical trials, received speaking fees from Bristol-Myers Squibb, Astra Zeneca, Janssen \& Cilag, Lundbeck, Servier, Otsuka Pharmaceuticals, and Eli Lilly and has acted as advisor to Astra Zeneca, Eli Lilly, Lundbeck, Otsuka Pharmaceuticals, Takeda, and Medivir.

\section{Availability of data and materials}

The data that support the findings of this study are available from Statistics Denmark and the Danish Health Authorities, but restrictions apply to the availability of these data, which were used under license for the current study, and so are not publicly available.

\section{Consent for publication}

All authors contributed to and approved the final manuscript and gave their consent for publication.

\section{Ethics approval and consent to participate}

The Danish Data Protection Agency approved the use of the data. No ethical research committee approval was needed as the anonymized data was obtained from the registers for statistical purposes only. The study was approved by Statistics Denmark (FSEID-00001245).

\section{Funding}

No external funding was required for the current study.

\section{Publisher's Note}

Springer Nature remains neutral with regard to jurisdictional claims in published maps and institutional affiliations.

Received: 11 October 2018 Accepted: 19 December 2018

Published online: 01 March 2019

\section{References}

Ashdown-Franks G, Williams J, Vancampfort D, Firth J, Schuch F, Hubbard K, Craig T, Gaughran F, Stubbs B. Is it possible for people with severe mental illness to sit less and move more? A systematic review of interventions to increase physical activity or reduce sedentary behaviour. Schizophrenia Res. 2018. https://doi.org/10.1016/j.schres.2018.06.058.

Björkman T, Angelman T, Jönsson M. Attitudes towards people with mental illness: a cross-sectional study among nursing staff in psychiatric and somatic care. Scand J Caring Sci. 2008;22(2):170-7. https://doi.org/10.111 1/j.1471-6712.2007.00509.x

Correll CU, Galling B, Pawar A, Krivko A, Bonetto C, Ruggeri M, Craig TJ, Nordentoft M, Srihari VH, Guloksuz S, Hui CLM, Chen EYH, Valencia M, Juarez F, Robinson DG, Schooler NR, Brunette MF, Mueser KT, Rosenheck RA, Marcy P, Addington J, Estroff SE, Robinson J, Penn D, Severe JB, Kane $J M$. Comparison of early intervention services vs treatment as usual for early-phase psychosis. JAMA Psychiatry. 2018;75(6):555. https://doi. org/10.1001/jamapsychiatry.2018.0623.

Davydow DS, Ribe AR, Pedersen HS, Fenger-Grøn M, Cerimele JM, Vedsted P, Vestergaard M. Serious mental illness and risk for hospitalizations and rehospitalizations for ambulatory care-sensitive conditions in Denmark. 
Med Care. 2016;54(1):90-7. https://doi.org/10.1097/MLR.0000000000 000448.

Fleischhacker WW, Cetkovich-Bakmas M, Hert M, Hennekens CH, Lambert M, Leucht S, Maj M, McIntyre RS, Naber D, Newdgcomer JW, Olfson M. Comorbid somatic illnesses in patients with severe mental disorders: clinical, policy, and research challenges. J Clin Psychiatry. 2008;69(4):514-9.

Hayes JF, Marston L, Walters K, King MB, Osborn DPJ. Mortality gap for people with bipolar disorder and schizophrenia: UK-based cohort study 2000-2014. Br J Psychiatry. 2017;211(3):175-81. https://doi.org/10.1192/ bjp.bp.117.202606.

Hayes JF, Miles J, Walters K, King M, Osborn DP. A systematic review and meta-analysis of premature mortality in bipolar affective disorder. Acta Psychiatrica Scandinavica. 2015. https://doi.org/10.1111/acps.12408.

Howard LM, Barley EA, Davies E, Rigg A, Lempp H, Rose D, Taylor D, Thornicroft G. Cancer diagnosis in people with severe mental illness: practical and ethical issues. Lancet Oncol. 2010;11(8):797-804. https://doi.org/10.1016/ S1470-2045(10)70085-1.

Jakobsen L, Terkelsen CJ, Christiansen EH, Maeng M, Jensen LO, Veien K, Raungaard B, Jensen SE, Mehnert F, Johnsen SP. Severe mental illness and clinical outcome after primary percutaneous coronary intervention. Am J Cardiol. 2017;120(4):550-5. https://doi.org/10.1016/j.amjcard.2017.05.021.

James M, Thomas M, Frolov L, Riano NS, Vittinghoff E, Schillinger D, Newcomer $J W$, Mangurian C. Rates of cervical cancer screening among women with severe mental illness in the public health system. Psychiatr Serv. 2017;68(8):839-42. https://doi.org/10.1176/appi.ps.201600293.

Julious SA, Nicholl J, George S. Why do we continue to use standardized mortality ratios for small area comparisons? J Public Health Med. 2001;23(1):40-6.

Kessing LV, Hansen HV, Hvenegaard A, Christensen EM, Dam H, Gluud C, Wetterslev J. Treatment in a specialised out-patient mood disorder clinic v. standard out-patient treatment in the early course of bipolar disorder: randomised clinical trial. Br J Psychiatry. 2013;202(3):212-9. https://doi. org/10.1192/bjp.bp.112.113548.

Kugathasan P, Laursen TM, Grøntved S, Jensen SE, Aagaard J, Nielsen RE. Increased long-term mortality after myocardial infarction in patients with schizophrenia. Schizophrenia Res. 2018. https://doi.org/10.1016/j.schre s.2018.03.015.

Laursen TM. Life expectancy among persons with schizophrenia or bipolar affective disorder. Schizophrenia Res. 2011;131(1-3):101-4. https://doi. org/10.1016/j.schres.2011.06.008.

Laursen TM, Munk-Olsen T, Agerbo E, Gasse C, Mortensen PB. Somatic hospital contacts, invasive cardiac procedures, and mortality from heart disease in patients with severe mental disorder. Arch Gen Psychiatry. 2009;66(7):713. https://doi.org/10.1001/archgenpsychiatry.2009.61.

Laursen TM, Nordentoft M. Heart disease treatment and mortality in schizophrenia and bipolar disorder - changes in the Danish population between 1994 and 2006. J Psychiatric Res. 2011;45(1):29-35. https://doi. org/10.1016/j.jpsychires.2010.04.027.

Laursen TM, Wahlbeck K, Hällgren J, Westman J, Ösby U, Alinaghizadeh H, Gissler M, Nordentoft M. Life expectancy and death by diseases of the circulatory system in patients with bipolar disorder or schizophrenia in the Nordic Countries. PLOS ONE. 2013;8(6):e67133. https://doi.org/10.1371/ journal.pone.0067133.

Lee EE, Liu J, Tu X, Palmer BW, Eyler LT, Jeste DV. A widening longevity gap between people with schizophrenia and general population: a literature review and call for action. Schizophr Res. 2018;196:9-13. https://doi. org/10.1016/j.schres.2017.09.005.

Lynge E, Sandegaard JL, Rebolj M. The Danish national patient register. Scand J Public Health. 2011;39(7 Suppl):30-3. https://doi.org/10.1177/14034 94811401482.

Manderbacka K, Arffman M, Suvisaari J, Ahlgren-Rimpiläinen A, Lumme S, Keskimäki I, Pukkala E. Effect of stage, comorbidities and treatment on survival among cancer patients with or without mental illness. Br J Psychiatry. 2017;211(05):304-9. https://doi.org/10.1192/bjp.bp.117.198952.

Mitchell AJ, Pereira IES, Yadegarfar M, Pepereke S, Mugadza V, Stubbs B. Breast cancer screening in women with mental illness: comparative meta-analysis of mammography uptake. Br J Psychiatry. 2014;205(06):428-35. https ://doi.org/10.1192/bjp.bp.114.147629.
Mitchell AJ, Vancampfort D, De Hert M, Stubbs B. Do people with mental illness receive adequate smoking cessation advice? A systematic review and meta-analysis. Gen Hosp Psychiatry. 2015;37(1):14-23. https://doi. org/10.1016/J.GENHOSPPSYCH.2014.11.006.

Moore DJ, Posada C, Parikh M, Arce M, Vaida F, Riggs PK, Gouaux B, Ellis RJ, Letendre SL, Grant I, Atkinson JH. HIV-infected individuals with cooccurring bipolar disorder evidence poor antiretroviral and psychiatric medication adherence. AIDS and Behavior. 2012;16(8):2257-66. https:// doi.org/10.1007/s10461-011-0072-2.

Mors O, Perto GP, Mortensen PB. The Danish psychiatric central research register. Scand J Public Health. 2011;39(7 Suppl):54-7. https://doi. org/10.1177/1403494810395825.

Naing NN. Easy way to learn standardization: direct and indirect methods. Malays J Med Sci. 2000;7:10-5.

Nielsen RE, Uggerby AS, Jensen SOW, McGrath JJ. Increasing mortality gap for patients diagnosed with schizophrenia over the last three decadesa Danish nationwide study from 1980 to 2010. Schizophrenia Res. 2013;146:1-3. https://doi.org/10.1016/j.schres.2013.02.025.

Nordentoft M, Wahlbeck K, Hällgren J, Westman J, Ösby U, Alinaghizadeh $H$, Gissler M, Laursen TM. Excess mortality, causes of death and life expectancy in 270,770 patients with recent onset of mental disorders in Denmark, Finland and Sweden. PLoS ONE. 2013;8(1):e55176. https://doi. org/10.1371/journal.pone.0055176.

Pedersen CB. The Danish civil registration system. Scand J Public Health. 2011;39(7 Suppl):22-5. https://doi.org/10.1177/1403494810387965.

Pérez-Piñar M, Mathur R, Foguet Q, Ayis S, Robson J, Ayerbe L. Cardiovascular risk factors among patients with schizophrenia, bipolar, depressive, anxiety, and personality disorders. Eur Psychiatry. 2016;35:8-15. https://doi. org/10.1016/j.eurpsy.2016.02.004.

Speyer H, Christian H, Birk M, Karlsen M, Storch Jakobsen A, Pedersen K, Hjorthøj C, Pisinger C, Gluud C, Mors O, Krogh J, Nordentoft M. The CHANGE trial: no superiority of lifestyle coaching plus care coordination plus treatment as usual compared to treatment as usual alone in reducing risk of cardiovascular disease in adults with schizophrenia spectrum disorders and abdominal obesity. World Psychiatry. 2016;15(2):155-65. https://doi.org/10.1002/wps.20318.

Staudt Hansen P, Frahm Laursen M, Grøntved S, Puggard Vogt Straszek S, Licht RW, Nielsen RE. Increasing mortality gap for patients diagnosed with bipolar disorder-a nationwide study with 20 years of follow-up. Bipolar Dis. 2018. https://doi.org/10.1111/bdi.12684.

Swildens W, Termorshuizen F, de Ridder A, Smeets H, Engelhard IM. Somatic Care with a Psychotic Disorder. Lower somatic health care utilization of patients with a psychotic disorder compared to other patient groups and to controls without a psychiatric diagnosis. Admin Policy Men Health Mental Health Serv Res. 2016;43(5):650-62. https://doi.org/10.1007/s1048 8-015-0679-0.

Teasdale SB, Ward PB, Rosenbaum S, Samaras K, Stubbs B. Solving a weighty problem: systematic review and meta-analysis of nutrition interventions in severe mental illness. Br J Psychiatry. 2017;210(02):110-8. https://doi. org/10.1192/bjp.bp.115.177139.

Thomas M, James M, Vittinghoff E, Creasman JM, Schillinger D, Mangurian C. Mammography among women with severe mental illness: exploring disparities through a large retrospective cohort study. Psychiatric Serv. 2018;69(1):48-54. https://doi.org/10.1176/appi.ps.201600170.

Uggerby P, Ostergaard SD, Roge R, Correll CU, Nielsen J. The validity of the schizophrenia diagnosis in the Danish Psychiatric Central Research Register is good. Danish Med J. 2013;60(2):4578.

Vancampfort D, Correll CU, Galling B, Probst M, De Hert M, Ward PB, Rosenbaum S, Gaughran F, Lally J, Stubbs B. Diabetes mellitus in people with schizophrenia, bipolar disorder and major depressive disorder: a systematic review and large scale meta-analysis. World Psychiatry. 2016;15(2):166-74. https://doi.org/10.1002/wps.20309.

Vancampfort D, Firth J, Schuch FB, Rosenbaum S, Mugisha J, Hallgren M, Probst M, Ward PB, Gaughran F, De Hert M, Carvalho AF, Stubbs B. Sedentary behavior and physical activity levels in people with schizophrenia, bipolar disorder and major depressive disorder: a global systematic review and meta-analysis. World Psychiatry. 2017;16(3):308-15. https://doi. org/10.1002/wps.20458. 
Vancampfort D, Stubbs B, Mitchell AJ, De Hert M, Wampers M, Ward PB, Rosenbaum S, Correll CU. Risk of metabolic syndrome and its components in people with schizophrenia and related psychotic disorders, bipolar disorder and major depressive disorder: a systematic review and metaanalysis. World Psychiatry. 2015;14(3):339-47. https://doi.org/10.1002/ wps.20252.
Wahlbeck K, Westman J, Nordentoft M, Gissler M, Laursen TM. Outcomes of Nordic mental health systems: life expectancy of patients with mental disorders. Br J Psychiatry. 2011;199(6):453-8. https://doi.org/10.1192/bjp. bp. 110.085100 .

\section{Submit your manuscript to a SpringerOpen ${ }^{\circ}$ journal and benefit from:}

- Convenient online submission

- Rigorous peer review

- Open access: articles freely available online

- High visibility within the field

- Retaining the copyright to your article

Submit your next manuscript at $\boldsymbol{\nabla}$ springeropen.com 